\title{
A CONTEMPLATIVE APPROACH TO CLINICAL SOCIOLOGY*
}

(C) Vincenzo M.B. Giorgino, Aggregate Professor Department of Economic and Social Sciences, Mathematics and Statistics State University of Torino (Italy) e-mail: vincenzo.giorgino@unito.it

*This paper is based on different previous presentations, in particular Understanding and compassion. Towards an integration between spiritual and sociological knowledge S.P.A. Annual Conference, Anaheim (CA, USA), 18th August 2001, unpublished; "Contemplative knowledge and sociological understanding", panel Contemplative understanding: a challenge to the sociological perspective, Sociological Practice Association (S.P.A.) Annual conference "Using Sociology for Good Purposes", San Francisco (CA, U.S.A.) August 17th 2004; unpublished. Both have been reviewed and integrated for the recent Workshop Wakeful inquiry: experiencing contemplative sociology in science and practice, held a the ISA RC46 Conference "Clinical Sociology: Improving Lives and Communities through Analysis and Intervention" Madrid, 16-19 March 2013.

Note: the pronoun indicating the first person singular is always written in minuscule character

Keywords: clinical sociology,

\section{The emergence of a professional culture}

The aim we commonly give to our action as sociologists, regardless of whether we are scientifically or practically oriented, can be defined in understanding. "Sociology is a science which attempts the interpretative understanding of social action in order to arrive at a causal explanation of its course and effects..." (Weber 1964, 88). The initial concept of understanding developed by our predecessors many years ago has been enriched and expanded in its original meaning. An expansion, and also an important innovation, of this view is represented by the collective effort of those who developed an applied and clinical perspective, which is oriented to give solid anchorage to professional understanding, not very well understood in our discipline, for its origins were marked by a natural science model. A similar model was successful in the other Western Countries after the 2nd World War, as happened in the fifties in Italy, where Sociology courses were first included in the academic setting. 


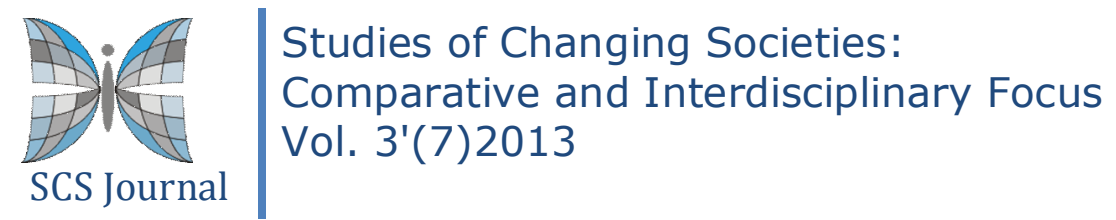

So far, intervention becomes a clear-cut concept, allowing us to develop and expand our creativity, leaving limitations based on scientific methodologies in favor of a professionally oriented approach oriented to master change at different levels: sociotherapy, health promotion, community intervention, conflict mediation, advocacy and so on (2).

The art of practicing intervention has its boundaries on the perspective based on a humanistic vision of our relationships. It is a quasi-commonsensical assumption the need for every sociologist to understand social events through a special kind of lens, which permits us to collect and analyze people's behavior through their cultural frameworks and it is a legacy of the so-called Chicago School and of the Weberian conception: two bricks in the foundation of our common house.

\section{Emotional work}

Another important wave of change is also represented by both the concept of sentimental work, which initially was introduced by Anselm Strauss in research on the health professions in hospital (1985), and the concept of emotional labor, developed mainly from a gender point of view by many women sociologists such as Russell Hochshild (1983) and Nicki James (1989). Before these contributions, we have poor references in our disciplines, with few authors such as Cooley, Simmel and Goffman as Wallace and Wolf reported. As the British sociologist Williams writes the 'irrational passion for a dispassionate rationality was prevalent in Western thought and practice" (Williams 1998, 747) and sociology was involved in it as well. As Seidler wrote:

[if] "... emotions get a scarce attention since recent times [it is] probably due to the fact that male academics [dominant in the discipline] prefer theories which make the reality of our own experience unreachable" and "men can analyze the state of the international capitalist economy better than issues in their personal lives" (Seidler 1985, 178, 172).

Recently, the North-American sociologist Randall Collins made explicit in his model of "interaction ritual chain" - as Wallace and Wolf comment- the key role of these emotional forces:

"As the emotional energy is an essential ingredient of it [the interaction ritual chain model, my note], he argues that the most basic ingredient in interactions is "a minimal tone of positive 


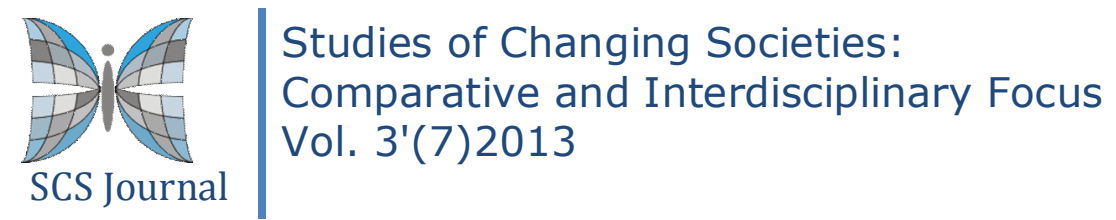

sentiment toward the other". Thus the individual who is accepted into a conversation, for instance, not only acquires an increment of positive emotional energy from that experience, but also additional emotional resources (confidence, warmth, enthusiasm) with which to negotiate successfully in the next interaction. Such chains, Collins says, "extend throughout every person's lifetime" " (Wallace and Wolf 1991, 284).

Emotions are considered as social forces, the intimate elements of our inner personal life have been discovered and publicized as sociological and not psychological. A similar conception is found, for example, in the field of sociotherapy (Cuthberson Johnson and Gagan 1993) and in the deep learning technique (Malhora Bentz 1992).

As Collins wrote "the human power of reasoning is based on non rational foundations, and that human society is held together not by rational agreements but by deeper emotional processes that produce social bonds of trust among particular kinds of people. Society is made up of groups. These groups are often in conflict with each other; but each group can operate only to the extent that each group is held together. That requires some nonrational mechanism producing common emotions and ideals..." (Collins 1992, vi).

Its neo-durkheimian approach leads us convincingly to recognize that our social contracts have a pre-contractual foundation and this can be called trust (ib.: 12).

But why does he talk about "nonrational" foundations? Collins remains attached to a divided thinking, typical of our Western culture since Descartes and Kant as summarized by Williams (1998). This British sociologist supports the idea that reasons and emotions are not antithetical, but complementary. As far as it looks commonsensical in everyday life, this is not an easy task in science, as he recognizes that "we need fundamentally [to] rethink existing epistemological models and ontological ways of being and knowing" (Williams, 1998).

In social psychology we get input about this issue from the key contribution of Stanley Greenspan (1997, see also Goleman 1996, 1998): throughout his research on difficult children, he developed the concept of emotional intelligence, which integrates cognitive rationality in a wider dimension.

These contributions could be considered the most important development of understanding from its conception in our discipline. 


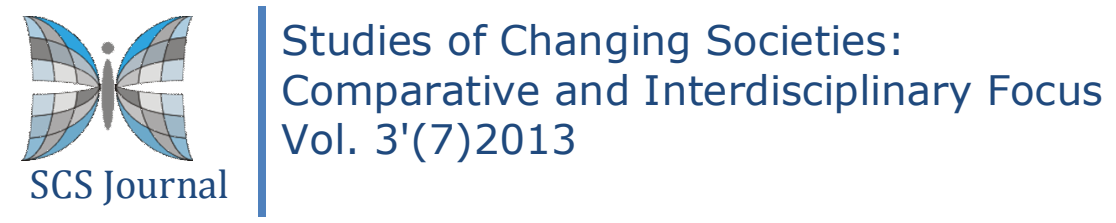

Emotions are now recognized as part of our intelligence, neither an irrational world to lay aside, nor a restricted area where only psychology could venture in. Emotional life should be interpreted today as a form of knowledge, which should be allowed to be more visible and public. Reasons for this stand in the social changes

affecting Western societies since the eighties; succinctly summarized in one word only: post-modernity.

Giddens, who prefers to call our period late modernity (1991), has emphasized that identities and their social construction are problems of our society. He recognizes the new role of knowledge and, specifically, the special role of that part of knowledge which is related to this construction, for which "self-identity becomes a reflexively organized endeavour" (Giddens 1991: 5).

"'Personal meaninglessness - the feeling that life has nothing worthwhile to offer - becomes a fundamental psychic problem in circumstances of late modernity" to quote again the renowned British sociologist.

The making of identities in groups, communities, organizations and societies is done with the growing contribution of the experts, who are mainly found within the rank and file of the human sciences' practitioners.

Empowering selves: this was the original claim that influenced the dominant emancipation culture (ib.: 9). Its aim is to support people from their disfranchisement by new forms of power in this globalised era. Marxists and liberal thinkers all pursue the same goal: emancipation in different forms. So far Giddens defines "emancipatory politics":

" a generic outlook concerned above all with liberating individuals and groups from constraints which adversely affect their life chances.

Emancipatory politics involves two main elements: the effort to shed shackles of the past, thereby permitting a transformative attitude towards the future; and the aim of overcoming the illegitimate domination of some individuals of groups by others" (ib.: 210-11).

Terms such as exploitation, inequality, oppression are related to it and to its definition of power is intended as an hierarchical notion. 


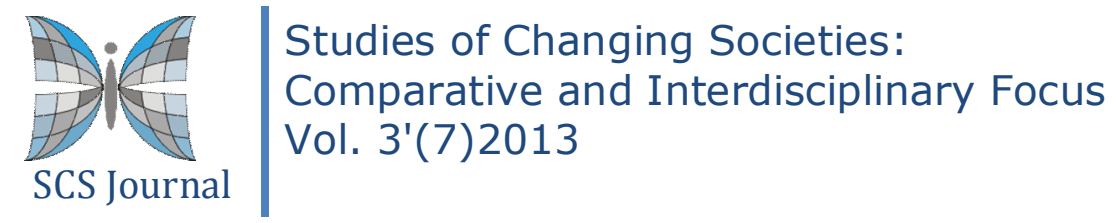

"Emancipatory politics makes primary the imperatives of justice, equality, and participation" (ib.: 212).

A common point is to empower individuals (Straus 1994), groups, communities, and societies to be able to manage their lives better. The same observation can be true for the area of study of emotions quoted above and for sociological interventions in favor or women's groups (Mancini Billson 1994, 1991; Hall 1993).

Giddens points out that feminism situated itself at the borders of emancipatory politics towards the new life politics. The latter being a politics of self-actualization:

"... [it] concerns political issues which flow from processes of selfactualization in post-traditional contexts, where globalising influences intrude deeply from the principal themes into the reflexive project of the self, and conversely where processes of selfrealizations influence global strategies (Giddens 1991: 214).

... self -identity today is a reflexive achievement. The narrative of selfidentity has to be shaped, altered and reflexively sustained in relation to rapidly changing circumstances of social life, on a local and global scale.

Only if the person is able to develop an inner authenticity - a framework of basic trust by means of which the lifespan can be understood as a unity against the backdrop of shifting social events can this be attained" (ib.: 215).

\section{In search of a meaning of life}

At this point it is important to focus the attention on a crucial element of social life. That is: impermanence, the human limit created by the definite time of our life span, even if undetermined still definite.

Impermanence it is a hard fact of life; nevertheless a "fact" which is removed from the sociological fabric. Evidence of it can be found in the introduction to the discipline in many textbooks. While people live and die society and groups and organizations survive individual's resignations, this permanence makes the creation and development of our discipline worthwhile: understanding how it works. Interpret the social world in order to manage it or to be able to make it available to us. 


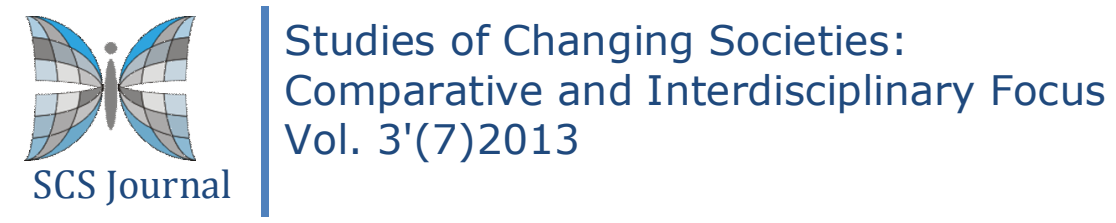

Impermanence: by itself is nothing new at all and so trivial that it does not need to be recalled in our talk. It is a very good starting point as it is the main source of our sufferance as human beings.

Our understanding (Wallace and Wolf 1991: see especially the first chapter) of social life can be reconsidered under this light: we are dying beings. The awareness of this is the starting point of a different insight.

Social attachments are precarious, because our life is precarious and temporary. Social attachments to power, money, sex, love relationships, work, drugs, practice or theoretical sociology, etc. are social constructions, "social illusions" in a moral language.

Along Collins "the production of moral feelings - trust -depends upon procedures called social rituals" (Collins 1992: 29). This means calling for a specific social institution: religion. As Collins argues: " Either you believe it or you don't, in one case it is a supreme Reality that transcends everything sociology is concerned with; in the other it is an irrational superstition about things that don't exist". And he concludes: "For the most part social thinkers have taken the second of these two attitudes" (ib.: 30).

'What all religions have in common, rather, are two things: certain beliefs held by all adherents and certain rituals (ib.: 33)". Not properly so: the fact is that any individual has in common with his fellow a spiritual culture. It is not believing in a kind of God, a transcendent entity, it is dealing with the kind of existential questions cited by Giddens (1991: 55, figure 2) (3).

Meditation or preaching are forms of knowledge, special techniques or methods with their roots in the spiritual tradition of mankind, which assist people and help them to manage this kind of questions. Neither metaphysical nor transcendental matter: it is neither a philosophical nor strictly religious argument, in the sense of institutionally organized beliefs and social rituals (Collins 1982); it is not irrational thinking (Collins 1982) versus rationality of science and professions. Just human stuff, just being reflective about our everyday life and relationships.

This is not a kind of argument to leave aside, as a matter for sociology of religion, or reduce as intimate and personal beliefs, as Collins suggested. This is the cultural change we need in our times: making public and sociologically relevant what was assigned to the realm of private affairs. It is too important to be marginalized in special areas of our discipline. It is common in sociology to identify 


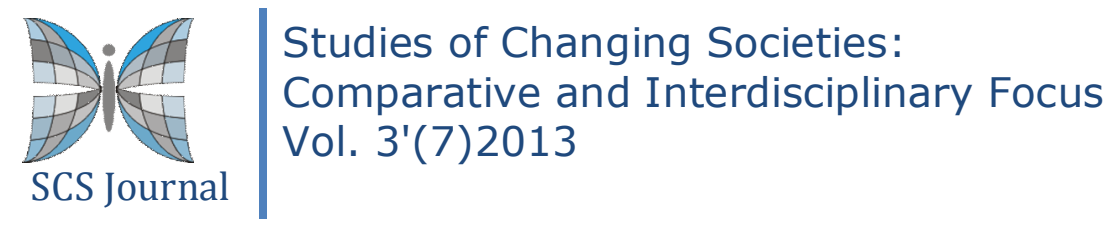

spirituality with religion and "to explain" the latter as Collins interestingly did in the above-mentioned essay.

Spiritual labor is a kind of work common to every man and woman on our planet. It is not about believing: it does not refer to a God, Allah, or animism. It is about the acknowledgment that life has no objective meaning. Spiritual work can be defined as to deal with the limitedness of our self (4). It is the practice of emotional and cognitive management of our impermanence through the course of our life.

Being aware of this condition is to understand our limits and opportunities.

The fullness of our social attachments, of the making of our identities and molding ourselves (see Mead in Wallace and Wolf 1991) has its counterpart in the void of the non-self: the labor of being aware, step by step, of the source of our unhappiness, impermanence.

We can interpret meditation practice as a type of knowledgeoriented action, which aim is to overcome our selves-reflection. We can observe ourselves from outside, a fundamental power of all human beings, with the aim to reach no aim. "Deconstructing" our social selves, dis-empowering us, our social identities, which does not mean cancel them, just self-surrendering.

Non-self means an effort to disempower ourselves, to deconstruct current cultural models founding our roles and statuses -any kind of them, marital, occupational, political and even spiritual ones. This is why personal experience in Buddhist psychology is considered as vacuity: self is a social construction, provisional.

The experience of non-self through the vehicle of meditation means something different and more complete than an intellectual understanding. Methods to disempower us cannot be reduced to social rituals as Collins argues. It is not a mystic affair, it is not about believing or not. It is just about trust; it is a social process embedded in a compassionate perspective.

\section{On interdependence}

Interdependence or interconnectedness of all social phenomena is a basic tenet common to the contemplative knowledge and sociology. It is at the root of no random human behavior, a founding element of our discipline. Nevertheless aims are different: the former looks at the emergence of interconnection and unity of multiple phenomena, 


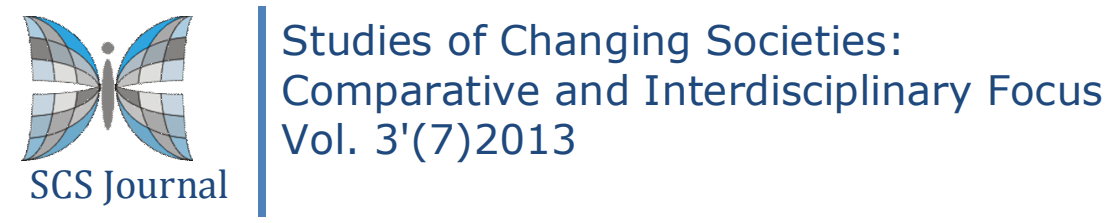

the latter aims to interpret the variety of cultural human patterns, practically or theoretically.

In the former, the interconnection of the variety of human behaviors, state of minds, social conditions etc. is interpreted as the process of being aware of transformation of multiple selves in oneness. It could be of help to consider an article by Humphrey (2000), which interprets the absence of a major self in early childhood as a structure of multiple separated sub-selves, not yet coordinated. He makes an analogy of the orchestra before the concert. Each of the players acts separately, - sitting down, adjusting their chair, starting to tune their instrument - without any conductor. Sometimes even in adulthood it is possible to experience this kind of separateness. Humphrey adds that the image of the child as a person is just a cultural image that belongs to his owner (the author). Ownership, belonging and bearing are all terms indicating a form of control and property over social reality, which we are so familiar with, that it is an assumption taken for granted. This sensation of not being an entire self can be compared to the voluntary experience of meditation, a sort of progressive achievement of a non self condition, absence of a conscious awareness of being, confusing the self with the context. No self, no identity: oneness.

In this direction, the collective energy based on trust, the basic tenet of social solidarity and of the interplay between human society and the rest of the natural world becomes a real experience of everyone and not an intellectual definition. Oneness is the outcome of the process of disempowering individual selves, recognizing the final unity. In one sentence: trust others, being one.

\section{The contemplative perspective in teaching}

I want to make a reference on my experience in Higher Education. The course of Sociology of Health i taught at the Nursing School of the Faculty of Medicine of the University of Turin (1998-2009) has been intended to familiarize the nursing students with the concept of health as a social construction. This conception, practice oriented, must allow the student to interpret social situation or processes of health and illness in a way to intervene successfully developing cultural sustainable actions.

The course is structured to enhance the growth of the student at cognitive, emotional and spiritual levels. Without giving a complete description (available in Fritz and Clark 1993) and making a partial 


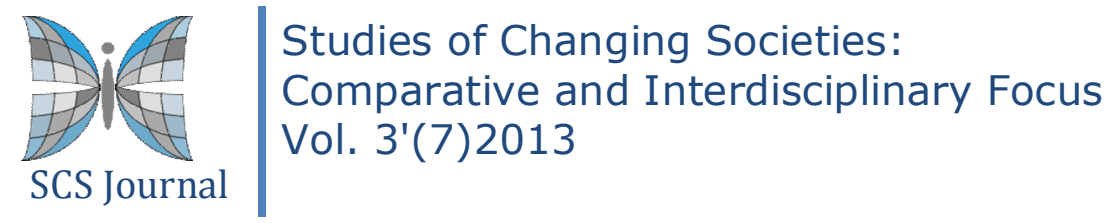

reference to the contents, i presented two research issues, which are very important in nursing training. One is about informal work and the second is about Personal Social service work. The first acquires its importance because draws attention to the large amount - in terms of quantity, as well as of quality - of work in the health setting given by non-professionals. In these difficult times for all the National Health systems, the recognition of this hidden work could be a good step in service re-organization to overcome better the contradictory needs for financial efficiency and efficacy $\backslash$ quality from the customer and the community point of view. In the specific case of the Italian situation, the relatively new entry (1994) of nurses in the academy represents in itself due recognition of the value of this profession. Nevertheless as a side effect, it could over emphasize in a negative way, the "professional values", along the lines of a medical model, seen as the successful one. It results in a misrepresentation of the informal work, which is considered lacking in scientific and professional expertise.

The second area of research is that of Personal social services. As a personal social service work, Nursing is a helping profession with traits common to education, social workers, teachers and so on. All of them are involved in a production-consumption process in which a service is provided and at the same time modified by caretaker's acts (Evers 1996). This definition challenges the nursing student attitude to see his/her profession as an "health profession"; a label, which usually includes a professional and organizational self-referenced definition of what is illness management or health promotion.

These cognitive elements, among others, can have positive side effects for students when coping with the social world around them. Be it that of other courses, anxious to legitimate the relatively new discipline in our context, be it the hospital or community services in which they go for the required compulsory training. In this sense, cognitive and emotional aspects are not seen as separate, but have to be seen as complementary and mutually influencing each other.

A self-reflection activity is offered in the workshops attached to the course. In the first of them, on health, the individual assignment is based on a self-questionnaire on well being, after which a small group discussion follows to share personal views of the attendants. The workshop is expected before the course starts, as a sort of "beginner's mind" exercise (Suzuki 1998). This allows the emergence of personal feelings and conceptions about well being which are not influenced yet by the School or the professional system. 


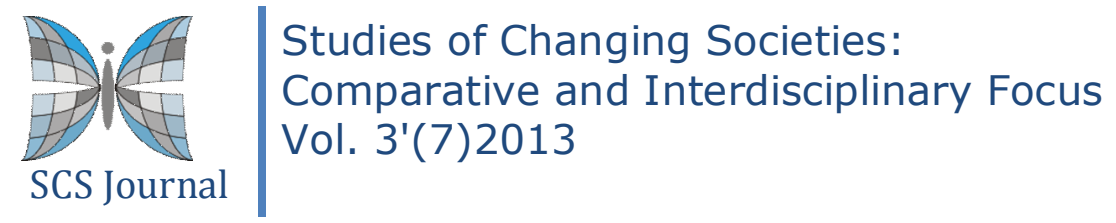

Another activity worth of mention is the interview on chronic illness management in the familiar, kin or community background that is what students expect, with particular attention to the informal work and to its interweaving with professional care in any setting crossed by the caretaker. Also this individual assignment is discussed in a small group session (5-7 members) (5).

In the academic year 2000-2001 i integrated the interview group discussion with a meditation session on the same day. The latter is intended to allow student to be acknowledged as having attained a specific method - sitting meditation - that allows them to obtain the insights described above.

The whole course is based on what could be considered as a grounded training approach, which will in some degree satisfy the need for a compassionate sociological education for Nursing students. The need for such training in higher education is now increasingly recognized as a basic pillar of the new post-modern society (Glazer 1999, Galtung 1999). In my opinion it answers the need for the so-called Scholarship of teaching and learning model (Atkinson 2001), and it represents also a way to overcome some of the historical problems encountered by the difficult marriage between Nursing and Sociology (Allen 2001).

\section{A secularized model for everyday life}

In recent years, the emerging cultural model based on a compassionate approach to social life, is generating interesting methods and techniques in different fields of social action such as peacekeeping (Thick Nhat Hahn 1989), social problems (Sivaranaksa 1999), higher education (Galtung 1999) and medical education (Remen 1999).

The sociological perspective could be of help in its specific oriented insights. In this two way process, both parties gain. One of the claims of post-modernity is to develop a lay spirituality, a kind of first issue in the agenda of current politics. The compassionate perspective, based on the insightful work of the professional sociologist, makes the difference between a sociological practice based on the opposite thinking and a practice oriented to integrate and make more spacious our understanding (Pensa 1994; Kornfield 2000). Nevertheless these introductory remarks call for a new perspective for both professional and scientific experiences in sociology: a new path to which an increasing number of colleagues i hope will be committed in the coming years. 


\section{Notes}

1) I read my first book on Clinical Sociology (Glassner and Freedman 1979) at the end of the 80s. Since then, i have proceeded to find my own way within the wider stream of sociological practice. I feel gratitude to the former SPA, a sentiment due to many factors, at this moment $i$ wish to refer specifically to the cultural gift the association has given me, which has helped me to enhance my awareness of the practical side of our discipline.

2) See Rebach and Bruhn 1991, Laue (1989), Fritz and Clark 1993, Mauksch 1993, Straus 1994.

3)[Existential questions] "... concern basic parameters of human life, and are 'answered' by everyone who goes on in the context of social activity" (Giddens, 65).

Following Giddens' thought, these questions presumed four ontological and epistemological element: 1) existence and being, 2) finitude and human life, 3 ) the experience of others, 4) the continuity of self-identity. As the reader can realizes, my concern is related to only the second of these elements.

4) Self has different definitions in the sociological and in the spiritual tradition to which i refer in this paper; the over-simplification $\mathrm{i}$ assumed does not affect the central issues of my argumentation.

5) Due to the affective and private dimensions that in our culture this issue assumes any student could deploy this assignment at any phase (the interview or the sharing phase with other colleagues). 


\section{REFERENCES}

Beck C. J. 1994 Niente di Speciale Vivere lo Zen, Astrolabio-Ubaldini, Roma (originally: 1993 Nothing Special Living Zen, San Francisco, Harper.

Collins, R. 1992 Sociological Insight. An Introduction to non-obvious sociology New York, Oxford University Press, second edition. First edition: 1982.

Cohen, H. 1994 "Sociology and You: Good Living" in Straus 1994.

Cuthberson-Johnson, B.A. e Gagan, RJ. 1993 "The Subjective Dimension of a Bipolar Family Education Support Group: A Sociology of Emotion Approach" in Clinical Sociology Review, Vol. 11.

Downes, D. e Rock, P. 1988 Understanding Deviance, London, MacMillan. Dunscombe, J. and Mardsen, D. 1993 "Love and Intimacy: The Gender Division of Emotion and 'Emotion Work' Sociology Vol. 27, N. 2, May.

Fritz, J.M. and Clark, E. 1993 "An overview of the field of Sociological Practice: the Development of Clinical Sociology and Applied Sociology" in Howery, C. B. et al. (eds.) Teaching Sociological Practice: a Resource Book, Washington D.C, American Sociological Association Teaching Resources Center.

Galtung, J. 1999 "Education and Buddhism" in Sivaraksa et al.1999.

Giddens, A. 1991 Modernity and Self-Identity. Self and Society in the Late Modern Age, Cambridge, Polity Press/Basil Blackwell.

Glazer, S. 1999 (ed.) The Heart of Learning, New York, PenguinPutnam Inc.

Glassner, B. and Freedman, J. 1979 Clinical Sociology, New York, Longman.

Goleman, D. 1998 Le emozioni che fanno guarire, Oscar Saggi Mondadori (orig. 1997 Healing Emotions, Boston, Shambala).

Goleman, D. 1996 L'intelligenza emotiva Rizzoli (originally: 1995 Emotional Intelligence (C) Goleman) 
Greenspan, S. I. 1997 L'intelligenza del cuore, Oscar Saggi Mondadori (orig. 1997 The Growth of the Mind, (C) Greeenspan).

Hall. M. 1993 "Women discussion Groups: Applications of Identity Empowerment Theory" in Clinical Sociology Review, Vol. 11.

Hochshild, A.R. 1983 Commercialization of Human Feeling, Berkeley, University of California Press.

Kornfield, J. 2000 After the Ecstasy the Laundry, London, Bantham Books.

Humphrey N. 2000 "One-Self: A Meditation on the Unity of Consciousness" Social Research Vol. 67, n.4, Winter.

James N. 1989 "Emotional labour: skill and work in the social regulation of feelings" The Sociological Review Vol. 37, Nºl February.

Laue, J. 1989 "Sociology as Advocacy: There are no Neutrals" in Sociological Practice, Vol.9.

Malhora Bentz, V. 1992 "Deep Learning Groups: Combining Emotional and Intellectual Learning" Clinical Sociology Review, Vol.10.

Mancini Billson, J. 1994, "Society and Self: Symbolic Interactionist Framework for Sociological Practice" Clinical Sociology Review, Vol. 12.

Mancini Billson, J. and Disch E. 1991 "Empowering Women: A Clinical Sociology Model for Working with Women in Groups" in Rebach and Bruhn 1991.

Mauksch, H. 1993 "Teaching of Applied Sociology opportunities and obstacles" in Howery, C. et al. (ed.) Teaching Sociological Practice: a resource book, Washington D.C., ASA Teaching Resource Center.

Parsons T. (1950) "The Prospects of Sociological Theory" American Sociological Review, Vol. 15, N. 1, February.

Pensa, C. 1994 La tranquilla passione, Rome, Ubaldini Editore.

Rebach, H.M. 1991 "Intervention in Clinical Sociology" in Rebach and Bruhn 1991. 

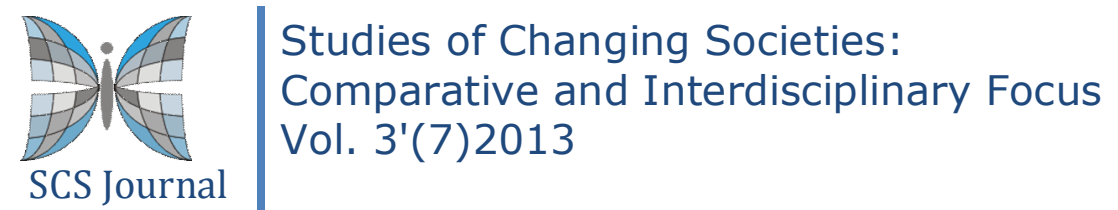

Rebach Howard M. and Bruhn, John G. 1991 (eds.) Handbook of Clinical Sociology, New York, Plenum Press.

Remen, R. N. 1999 "Educating or mission, meaning and compassion" in Glazer 1999.

Schwartz, H. and Jacobs, J. 1987 Sociologia qualitativa, Bologna, II Mulino. Originally: 1979 Qualitative Sociology. A method to the Madness, New York, The Free Press.

Seidler, V.J. 1985 "Fear and Intimacy" in Metcalf A.and Humphries M. (eds.) The Sexuality of Men, London, Pluto (cited in Dunscombe and Marsden 1993, 222). Sivaraksa, S. et al. (eds.) 1999 Socially Engaged Buddhism for the New Millennium, The

Satirakoses-Nagapradipa Foundation - The Foundation for Children.

Straus, R. 1994 (ed.) Using Sociology, New York, General Hall.

Strauss A. et al. 1985 he social organization of medical work,Chicago, The University of Chicago Press.

Suzuki, S. 1998 Zen mind, Beginner's mind, New York, Weatherhill.

Thich Nhat Hahn 1989 Essere Pace, Ubaldini Editore (English version: 1985 Being Peace, Berkeley, Parallax Press).

Wallace R.A. and Wolf A. 1991 Contemporary Sociological Theory. Continuing the Classical Tradition, Englewood Cliffs/New Jersey, Prentice-Hall Inc.

Weber, M. 1964 The Theory of Social and Economic Organization, New York, Oxford University Press, (in Wallace and Wolf 1991: 238)

Williams, S.J. 1998 "Modernity and the Emotions: Corporeal reflections on the Irrational" Sociology, Vol. 32, N.4, November. 